\title{
Health and Social Care Utilisation
}

\author{
Catriona Murphy, Patrick Moore, Sheena McHugh, \\ Hugh Nolan
}

\section{Contents}

Key Findings 124

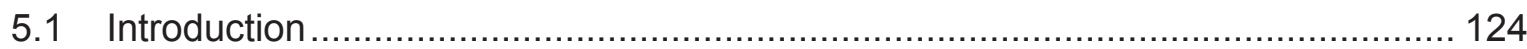

5.2 Medical card and private health insurance coverage ....................................... 125

5.3 Changes in medical card and private health insurance coverage ...................... 128

5.4 Utilisation of primary and secondary care services ......................................... 129

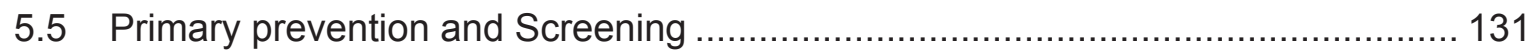

5.5.1 Prostate cancer screening ............................................................. 131

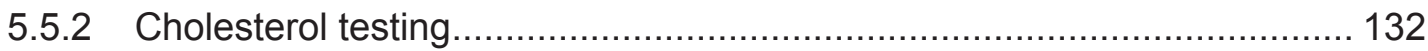

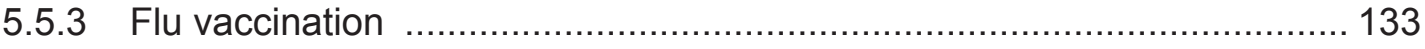

5.4.4 Breast Cancer Screening ................................................................. 133

5.6 Utilisation of community-based state care services......................................... 134

5.7 Disability prevalence and utilisation of home care services ................................ 135

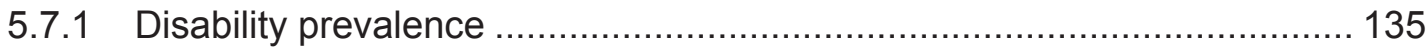

5.7.2 Utilisation of home help, personal care and meals services .................. 137

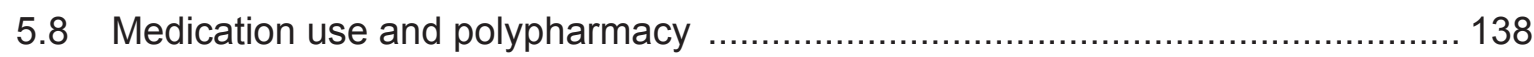

5.8.2 Use of generics: the case of Atorvastatin ............................................ 141

5.9 Health service utilisation at the end of life ....................................................... 143

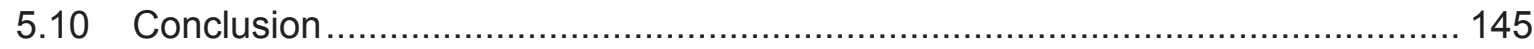

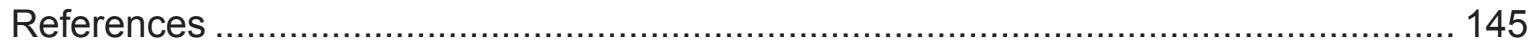

Appendix 5A: Tables on Health and Social Care Utilisation ................................... 147

Appendix 5B: Figures on Health and Social Care Utilisation..................................... 152 


\section{Health and Social Care Utilisation}

\section{Key Findings}

- The proportion of TILDA participants with a medical card or GP visit card increased overall between wave 1 and wave 2 (from $52 \%$ to $57 \%$ ), but declined in those aged $70+$ years.

- Between wave 1 and wave 2, private health insurance cover declined in those under 65 years and increased in those aged over 65 years.

- In wave 2, $21.1 \%$ of participants aged $80+$ years old had attended an Emergency Department (ED) at least once in the previous year (the corresponding figure for wave 1 was $15.1 \%)$.

- Utilisation of community health and social care services by the older population remains low.

- The uptake of prostate cancer screening services in men and breast cancer screening services women is high but the uptake of flu vaccination is low, particularly for those who do not have a medical or GP visit card.

- Polypharmacy (i.e., taking five or more medications) has increased from $21 \%$ at wave 1 to $26 \%$ at wave 2 .

- Participants who had died between wave 1 and wave 2 had higher levels of secondary care service utilisation (ED visits and hospital admissions) than survivors.

\subsection{Introduction}

Health service utilisation was reported in the first wave of TILDA on all those aged 50 years and over. This chapter reports on the health service utilisation two years later in those aged 52 years and older who took part in the second wave of the study $(n=7,134)$. This includes 7,010 participants who took part in both waves and 124 new participants. New participants in wave 2 include those previously deemed eligible to participate in wave 1 but who declined to do so at that time $(n=122)$ and new partners/spouses of study participants $(n=2)$. Wave 2 participants are therefore slightly older on average than participants in wave 
1 (mean age 65.5 years vs $63.8 \mathrm{yrs}$ ).

In this chapter an expanded age categorisation is used to highlight the different patterns of service utilisation with increasing age, as well as differing public healthcare entitlements by age. Although differences in the cohort between the first and second waves of TILDA are discussed in detail in Chapter 7, differences across the age groups are highlighted here due to their relevance in the context of health service utilisation. The youngest age group (52-59 years) in wave 2 is systematically different to the youngest age group in wave 1 which included participants aged $50-52$ years. The oldest age group ( $\geq 80$ years) are also older than the corresponding group in wave 1 (mean age 84.4 years vs 83.8 years). This reflects differences in eligibility to participate between the waves. In wave 2 it became possible to interview participants or their proxy where the participant had been admitted to a nursing home or had become cognitively impaired.

The chapter begins with a focus on health care entitlement status followed by utilisation of primary, secondary, community and home based services. The focus then turns to changes in prescribing patterns for older adults between the two waves. The final part of the chapter reports on health service utilisation in participants who died between wave 1 and wave 2 of the TILDA study.

\subsection{Medical card and private health insurance coverage}

There are two main categories of eligibility for public health services in Ireland, those with a medical card and those without. Those with a medical card are entitled to free General Practitioner (GP) care and public hospital services, free prescribed drugs and medicines subject to a $€ 2.50$ charge per item (from 1 December 2013), free dental, optical and aural services subject to certain limitations and a range of community care and personal social services. Eligibility for a medical card is means tested with different income thresholds applied at different ages. Those who do not meet the eligibility criteria for a medical card may qualify for a GP visit card, where the income thresholds are $50 \%$ higher than those for the medical card. The GP visit card entitles the holder to free GP visits; however, unlike the medical card the holder must pay out of pocket for all prescribed drugs and medicines. Under the Drugs Payment Scheme, all those without a medical card must pay the full cost of prescribed drugs and medicines up to a monthly deductible limit of $€ 144$ per family.

Universal entitlement to a medical card for all adults over 70 years was introduced in 2001 . This universal entitlement was removed in 2009 and an income threshold for eligibility reintroduced. The over 70 s income threshold has subsequently been revised downwards 
on an annual basis. During wave 2, a single person aged 70 years and older with a gross income of $€ 700$ per week or less or a couple over 70 years with a gross income of $€ 1,400$ per week or less qualified for a medical card under the scheme. Under The Health (Alteration of Criteria for Eligibility) Act 2013 this was revised downwards to $€ 600$ for a single person and $€ 1,200$ for a couple (1). The income thresholds for a medical card for persons over 70 years will be further reduced in 2014 to $€ 500$ per single person or $€ 900$ per couple (2)

During wave 2 adults over 70 years with a gross weekly income of over $€ 600$ but not exceeding $€ 700$ for a single person (over $€ 1,200$ and not exceeding $€ 1,400$ for a couple) were entitled to a GP visit card (3). Prescription charges were subsidised above a threshold of $€ 132$ per month under the Drugs Payment Scheme during the data collection period for wave 2, and this was increased to $€ 144$ per month from 1 January 2013.

Those without a medical card or GP visit card must pay out of pocket for GP services. This group are entitled to free public hospital services subject to in-patient and out-patient hospital charges, subsidised prescription charges under the Drugs Payment Scheme and have no entitlement to personal social services. Supplementary private health insurance is purchased by many individuals in order to gain quicker access to hospital services. Some individuals with entitlement to a medical card or GP visit card purchase private health insurance in addition to these entitlements; this group is described as having 'dual cover' in this report. Those without private health insurance, a GP visit card or a medical card are described as having 'no cover' in this report.

During the period between wave 1 and wave 2 (wave 1 commenced in 2009, wave 2 in 2012), due to the impact of the economic recession in Ireland, the number of Irish people eligible for medical cards increased and the number purchasing private health insurance decreased. In this period, the proportion of people with medical cards in the Irish population increased from 33.2\% (1.4 million) at the beginning of 2010 to $37 \%$ (1.7 million) at the beginning of 2012. The proportion of the population with GP visit cards also increased from $2.2 \%(98,300)$ to $3.1 \%(142,500)$ in the same time period $(4,5)$.

For ease of comparison with wave 1, Table 5.1 shows the pattern of health care cover for all participants aged 50 years and older in wave 1 and Table 5.2 shows the pattern in all participants aged 52 years and older in wave 2 . Due to the small number of participants with GP visit only cards this category is combined with the medical card category. The first four columns provide information on exclusive categories, i.e., an individual can belong to one category only. The sixth column 'All medical cards' combines the two categories 
of 'Medical card only' and 'Dual cover'. The seventh column 'All private health insurance' combines the two categories 'Private health insurance only' and 'Dual cover'.

Table 5.1: Health care entitlement status at wave 1 by age

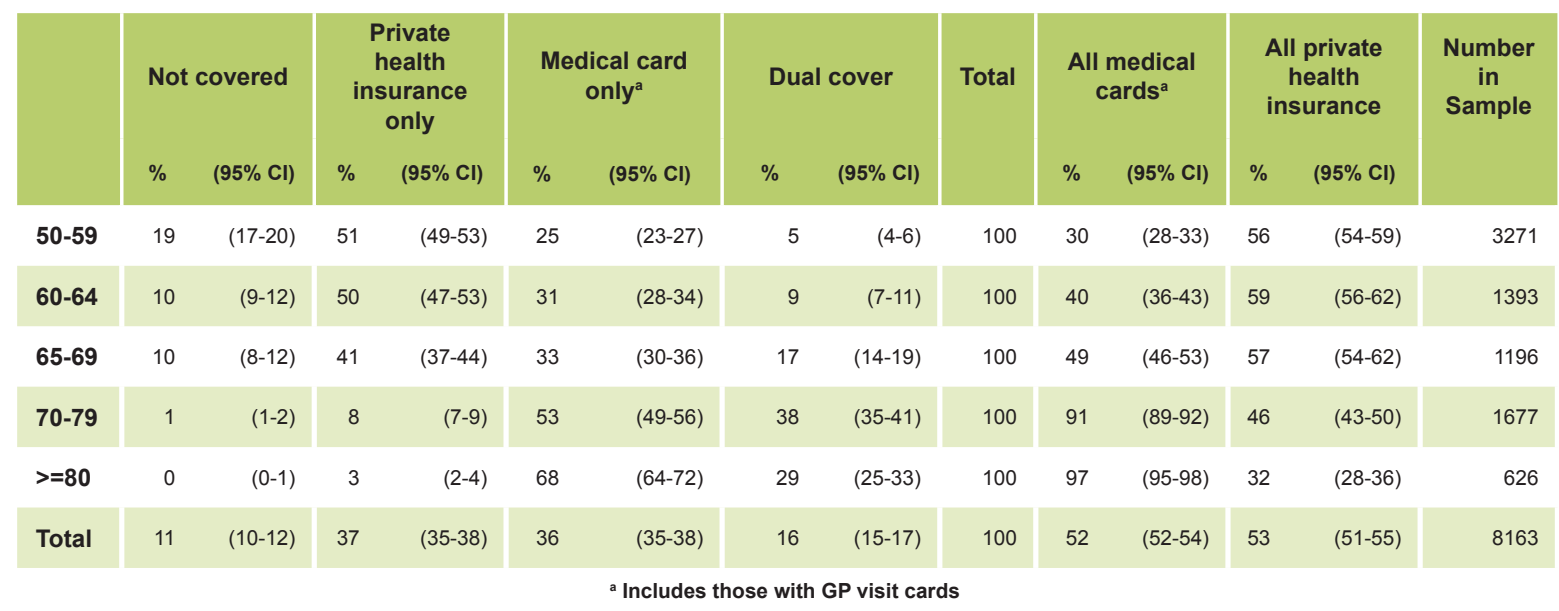

Table 5.2: Health care entitlement status at wave 2 by age

\begin{tabular}{|c|c|c|c|c|c|c|c|c|c|c|c|c|c|c|}
\hline & \multicolumn{2}{|c|}{ Not covered } & \multicolumn{2}{|c|}{$\begin{array}{c}\text { Private } \\
\text { health } \\
\text { insurance } \\
\text { only }\end{array}$} & \multicolumn{2}{|c|}{$\begin{array}{l}\text { Medical card } \\
\text { only }^{\mathrm{a}}\end{array}$} & \multicolumn{2}{|c|}{ Dual cover } & \multirow[t]{2}{*}{ Total } & \multicolumn{2}{|c|}{$\begin{array}{c}\text { All medical } \\
\text { cards }^{\mathrm{a}}\end{array}$} & \multicolumn{2}{|c|}{$\begin{array}{l}\text { All private } \\
\text { health } \\
\text { insurance }\end{array}$} & \multirow[t]{2}{*}{$\begin{array}{l}\text { Number } \\
\text { in } \\
\text { Sample }\end{array}$} \\
\hline & $\%$ & $(95 \% \mathrm{Cl})$ & $\%$ & $(95 \% \mathrm{Cl})$ & $\%$ & $(95 \% \mathrm{Cl})$ & $\%$ & $(95 \% \mathrm{Cl})$ & & $\%$ & $(95 \% \mathrm{Cl})$ & $\%$ & $(95 \% \mathrm{Cl})$ & \\
\hline $52-59$ & 18 & $(16-20)$ & 48 & $(46-51)$ & 27 & $(25-30)$ & 6 & $(5-7)$ & 100 & 34 & $(31-36)$ & 54 & $(52-57)$ & 2344 \\
\hline $65-69$ & 7 & $(5-9)$ & 42 & $(38-45)$ & 35 & $(32-38)$ & 17 & $(14-19)$ & 100 & 52 & $(48-55)$ & 58 & $(55-62)$ & 1182 \\
\hline $70-79$ & 1 & $(0-1)$ & 10 & $(9-12)$ & 50 & $(46-53)$ & 39 & $(36-42)$ & 100 & 89 & $(87-90)$ & 50 & $(46-53)$ & 1579 \\
\hline
\end{tabular}

The second wave of TILDA provides information on changing eligibility for free public health care in Ireland. While most of the changes between waves are not statistically significant, some interesting patterns emerge. Overall, the proportion of participants with medical /GP visit cards has increased from $52 \%$ at wave 1 (see Table 5.1 ) to $57 \%$ in wave 2 (see Table 5.2). This increase however is confined to those aged less than 70 years. The proportion with a medical/GP visit card decreased from $91 \%$ to $89 \%$ between waves in those aged $70-79$ years and from $97 \%$ to $95 \%$ between waves in those aged 80 years and older. In total $92 \%$ of participants aged 70 years and older have a medical card or GP visit card in wave 2.

A similar but opposite pattern can be seen in relation to private health insurance. The 
overall proportion of the older population with private health insurance is slightly reduced from $53 \%$ at wave 1 to $52 \%$ at wave 2 (see Table 5.1 and Table 5.2). A decrease in the proportion with private health insurance can be seen in those aged under 65 years and an increase in those aged 65 years and older, although none of these comparisons are statistically significant. The largest increase between the two waves can be seen in the 7079 year age group where $46 \%$ had private health insurance at wave 1 compared to $50 \%$ at wave 2.

The increase in private health insurance uptake at older ages is consistent with reports on the current age profile of the private health insurance market in Ireland. The numbers of people aged 60 years and over with private health insurance have increased annually between 2009 and 2011 compared to annual decreases in all age groups younger than 60 years (6). As the income thresholds for entitlement to a medical card among the over 70 s have been reduced recently, this increase in uptake of private health insurance may suggest a need for reassurance by older people that they have sufficient cover in the event of need for health care.

Recently published data from the Central Statistics Office revealed that $44 \%$ of Irish adults aged 65 years and older had private health insurance in 2011 (7). Using this age as a cutoff point, $46.5 \%$ of TILDA participants were found to have private health insurance in wave 1 and $48 \%$ to have private health insurance in wave 2 , representing a gradual increase in private health insurance uptake in this age group in the inter-wave period.

Almost a fifth of older adults have dual cover (private health insurance in addition to a medical/GP visit card). Dual cover is uncommon in the 52-59 year age group and is relatively static between the two waves in those under 70 years. The proportion of the population with no cover has changed little across the waves.

\subsection{Changes in medical card and private health insurance coverage}

To examine transitions in health care entitlement categories between wave 1 and wave 2, in this sub-section we focus just on individuals that took part in both waves and provided details of their health care entitlement status at both waves $(n=6,904)$. Table 5.3 provides detailed information on the transitions from wave 1 to wave 2 between the five mutually exclusive health care entitlement categories defined in Tables 5.1 and 5.2. 
Table 5.3: Changes in health care entitlement status between wave 1 and wave 2

\begin{tabular}{|c|c|c|c|c|c|c|c|}
\hline & $\begin{array}{c}\begin{array}{c}\text { Medical } \\
\text { card } \\
\text { only } \\
\text { (wave 2) }\end{array} \\
\%\end{array}$ & $\begin{array}{c}\begin{array}{c}\text { GP card } \\
\text { only } \\
\text { (wave 2) }\end{array} \\
\%\end{array}$ & $\begin{array}{c}\text { Private } \\
\text { health } \\
\text { insurance } \\
\text { only } \\
\text { (wave 2) } \\
\%\end{array}$ & $\begin{array}{c}\text { Dual private } \\
\text { Health } \\
\text { Insurance } \\
\text { plus } \\
\text { Medical/GP } \\
\text { Card } \\
\text { (wave 2) } \\
\%\end{array}$ & $\begin{array}{c}\text { No Cover } \\
\text { (wave 2) } \\
\\
\%\end{array}$ & $\begin{array}{c}\text { Total } \\
\\
\%\end{array}$ & $\begin{array}{c}\text { Number } \\
\text { in } \\
\text { sample } \\
\text { (wave 1) }\end{array}$ \\
\hline Medical card only (wave 1) & 96.0 & 0.3 & 0.3 & 2.4 & 1.0 & 100 & 2,001 \\
\hline GP card only (wave 1) & 42.2 & 29.8 & 0.0 & 1.2 & 26.8 & 100 & 62 \\
\hline $\begin{array}{l}\text { Private health insurance only } \\
\text { (wave 1) }\end{array}$ & 1.0 & 0.1 & 87.0 & 8.9 & 3.0 & 100 & 2,929 \\
\hline $\begin{array}{l}\text { Dual private health } \\
\text { insurance plus medical card/ } \\
\text { GP card (wave 1) }\end{array}$ & 10.5 & 0.3 & 4.9 & 83.9 & 0.5 & 100 & 1,201 \\
\hline No cover (wave 1) & 20.5 & 3.8 & 4.5 & 0.9 & 70.2 & 100 & 711 \\
\hline Number in sample (wave 2) & 2210 & 60 & 2682 & 1334 & 618 & 100 & 6904 \\
\hline
\end{tabular}

Of those who had a medical card only at wave 1 , almost all continued to have a medical card only at wave $2(96 \%)$ and a small proportion had purchased private health insurance in addition to their medical card cover by wave $2(2.4 \%)$ (see Table 5.3 ). While the number of participants with a GP visit card only at wave 1 was small, less than a third of these continued to have a GP visit card only at wave $2,42.2 \%$ had obtained a medical card and $26.8 \%$ had no cover at wave 2 . Almost $96 \%$ of those with private health insurance only at wave 1 retain their private health insurance alone or in conjunction with a medical card or GP visit card in wave 2 with a small proportion (3\%) transitioning to no cover. This contrasts with those who held private health insurance in addition to either a medical card or a GP visit card at wave 1, a proportion of whom have relinquished their private health insurance in the inter-wave period and now rely more heavily on a medical card only $(10.5 \%)$. Of those with no cover at wave $1,70.2 \%$ continued to have no cover at wave 2 and $20.5 \%$ had become eligible for a medical card with only $3.8 \%$ becoming eligible for a GP visit card.

\subsection{Utilisation of primary and secondary care services}

Primary and secondary care service utilisation increased between wave 1 and wave 2 . Utilisation of GP services remains high with $89.6 \%$ of participants in wave 2 indicating that they had visited their GP at least once in the previous year compared to $87.4 \%$ in wave 1 (see Table 5.4). Utilisation was highest in those with dual cover, followed by those with medical or GP visit cards. The lowest level of utilisation was found in those classified as having no cover. 
Frequency of GP visiting was examined at wave two. One tenth of those aged 52 years and older did not visit a GP in the previous year and $63 \%$ visited between one and four times, $25 \%$ visited between 5 and 19 times and only $2 \%$ visited 20 or more times in the previous year (See Appendix Table 5.A1). Frequency increased with age however a similar pattern can still be seen in those aged 80 years and older where $5 \%$ did not visit a GP in the previous year, $53 \%$ visited $1-4$ times, 39\% visited $5-19$ times and $3 \%$ visited a GP 20 times or more.

Table 5.4: Proportion utilising primary and secondary care services by age and health care entitlement status

\begin{tabular}{|c|c|c|c|c|c|c|c|c|}
\hline & \multicolumn{2}{|c|}{ GP visit (\%) } & \multicolumn{2}{|c|}{$\begin{array}{l}\text { Outpatient } \\
\text { visit (\%) }\end{array}$} & \multicolumn{2}{|c|}{$\begin{array}{l}\text { Emergency } \\
\text { Department } \\
\text { (ED) visit (\%) }\end{array}$} & \multicolumn{2}{|c|}{$\begin{array}{c}\text { Hospital } \\
\text { Admission } \\
(\%)\end{array}$} \\
\hline & $\begin{array}{c}\text { wave } \\
1\end{array}$ & $\begin{array}{c}\text { wave } \\
2\end{array}$ & $\begin{array}{c}\text { wave } \\
1\end{array}$ & $\begin{array}{c}\text { wave } \\
2\end{array}$ & $\begin{array}{c}\text { wave } \\
1\end{array}$ & $\begin{array}{c}\text { wave } \\
2\end{array}$ & $\begin{array}{c}\text { wave } \\
1\end{array}$ & $\begin{array}{c}\text { wave } \\
2\end{array}$ \\
\hline \multicolumn{9}{|l|}{ Age } \\
\hline $\begin{array}{l}50-59 \text { (wave 1) } \\
52-59 \text { (wave 2) }\end{array}$ & 80.7 & 84.3 & 35.7 & 38.6 & 14.0 & 14.4 & 10.5 & 10.2 \\
\hline $60-64$ & 88.0 & 88.0 & 42.0 & 42.2 & 14.3 & 14.0 & 11.3 & 11.3 \\
\hline $65-69$ & 90.8 & 91.7 & 45.2 & 51.0 & 16.0 & 15.9 & 15.0 & 14.7 \\
\hline $70-79$ & 94.7 & 94.7 & 46.2 & 51.5 & 16.7 & 19.4 & 16.6 & 18.2 \\
\hline$>=80$ & 95.4 & 94.1 & 36.9 & 47.0 & 15.1 & 21.1 & 15.6 & 24.8 \\
\hline Total & 87.4 & 89.6 & 40.2 & 45.0 & 14.9 & 16.4 & 12.9 & 14.6 \\
\hline \multicolumn{9}{|l|}{ Health entitlement status } \\
\hline Not covered & 74.3 & 75.1 & 31.3 & 31.2 & 13.2 & 11.6 & 5.9 & 6.8 \\
\hline $\begin{array}{l}\text { Private health insurance } \\
\text { only }\end{array}$ & 82.3 & 86.0 & 36.9 & 39.3 & 11.8 & 12.5 & 10.0 & 9.8 \\
\hline Medical/GP visit card only & 93.0 & 92.8 & 43.3 & 49.4 & 18.0 & 19.5 & 15.9 & 16.9 \\
\hline Dual cover & 95.3 & 97.0 & 46.8 & 53.1 & 16.2 & 19.7 & 17.1 & 22.6 \\
\hline Total & 87.4 & 89.6 & 40.2 & 45.0 & 14.9 & 16.5 & 12.9 & 14.6 \\
\hline
\end{tabular}

The proportion of older adults attending hospital as on outpatient in the year prior to the survey has increased by almost 5 percentage points between wave 1 and wave 2 (see Table 5.4). Utilisation increased the most between the two waves in those with dual cover and those with medical or GP visit cards only. The increase is especially apparent in those over 80 years where the proportion attending hospital as an outpatient in the previous year increased by over 10 percentage points between the two waves ( $36.9 \%$ to $47 \%)$. The increase in outpatient activity found at wave 2 may reflect a changing waiting pattern for outpatient services which came about as a result of the Department of Health's Special 
Delivery Unit (SDU). The SDU was set up in 2011 by the Minister for Health and tasked with implementing performance improvement in Irish hospitals. One of the targets set was to reduce outpatient waiting lists to no more than 12 months in the 2011 period and to reduce this further to 9 months in 2012. As a result there was an increase in activity in the outpatient sector aimed at addressing those who had been waiting longest.

Utilisation of emergency department (ED) services in the year prior to the survey increased slightly between waves 1 and 2 of TILDA (see Table 5.4). Utilisation was highest and increased the most in those with dual cover. The largest increase in ED utilisation can be seen in those aged 80 years and older. Just over $15 \%$ of this age group reported an ED visit in the first wave compared to $21.1 \%$ in wave 2 (see Table 5.4). Some of this change is likely due to the older age profile of those over 80 years in wave 2. Given the high levels of multi-morbidity in older adults, this finding highlights the need for service providers to actively consider the needs of this older age group in EDs and to provide renewed focus on primary care and community-based interventions which aim to reduce dependency on the ED.

Admission to hospital in the previous year has also increased in the older age group $80+$ years) in wave $2 ; 24.8 \%$ of those aged 80 and over had experienced at least one admission in the previous year compared to $15.6 \%$ in wave 1 .

\subsection{Primary prevention and Screening}

\subsubsection{Prostate cancer screening}

Excluding non-melanoma skin cancer, prostate cancer is the most frequently diagnosed cancer in men in Ireland (8). There is no population-based screening programme for prostate cancer in Ireland due to insufficient evidence to recommend the introduction of a prostate cancer screening programme (9). Despite this, there is widespread screening at a local level. The majority of men in TILDA have had a prostate cancer test (an examination of their prostate to screen for cancer or a Prostate Specific Antigen (PSA) test). In wave 1 $72.8 \%$ of men aged 50 years and older indicated that they had previously had a prostate cancer test. At wave 2 this proportion rose to $81.8 \%$ in those aged 52 years and older (see Table 5.5).

As this test is not population-based, health care entitlement status provides an insight into the pattern of uptake. A higher proportion of those with private health insurance (either in combination with a medical/GP visit card or private health insurance only) had prostate 
cancer screening carried out compared to those with a medical or GP visit card only or those with no cover (in both waves). Overall the proportion of men being screened for prostate cancer is high suggesting perceived importance of this test and a willingness to pay for this service even in the group of men classified as having no cover.

Men who indicated that they had a PSA test carried out at wave 1 were asked in wave 2 if they had a repeat test conducted since the time of their first interview. Almost $79 \%$ had a repeat test carried out between the two waves. Men who had not been tested at the time of their first interview were asked if they had been tested between the two waves. In this group $44 \%$ were found to have been tested for the first time in the inter-wave period.

Table 5.5: Proportion utilising primary and secondary prevention services by age and health care entitlement status

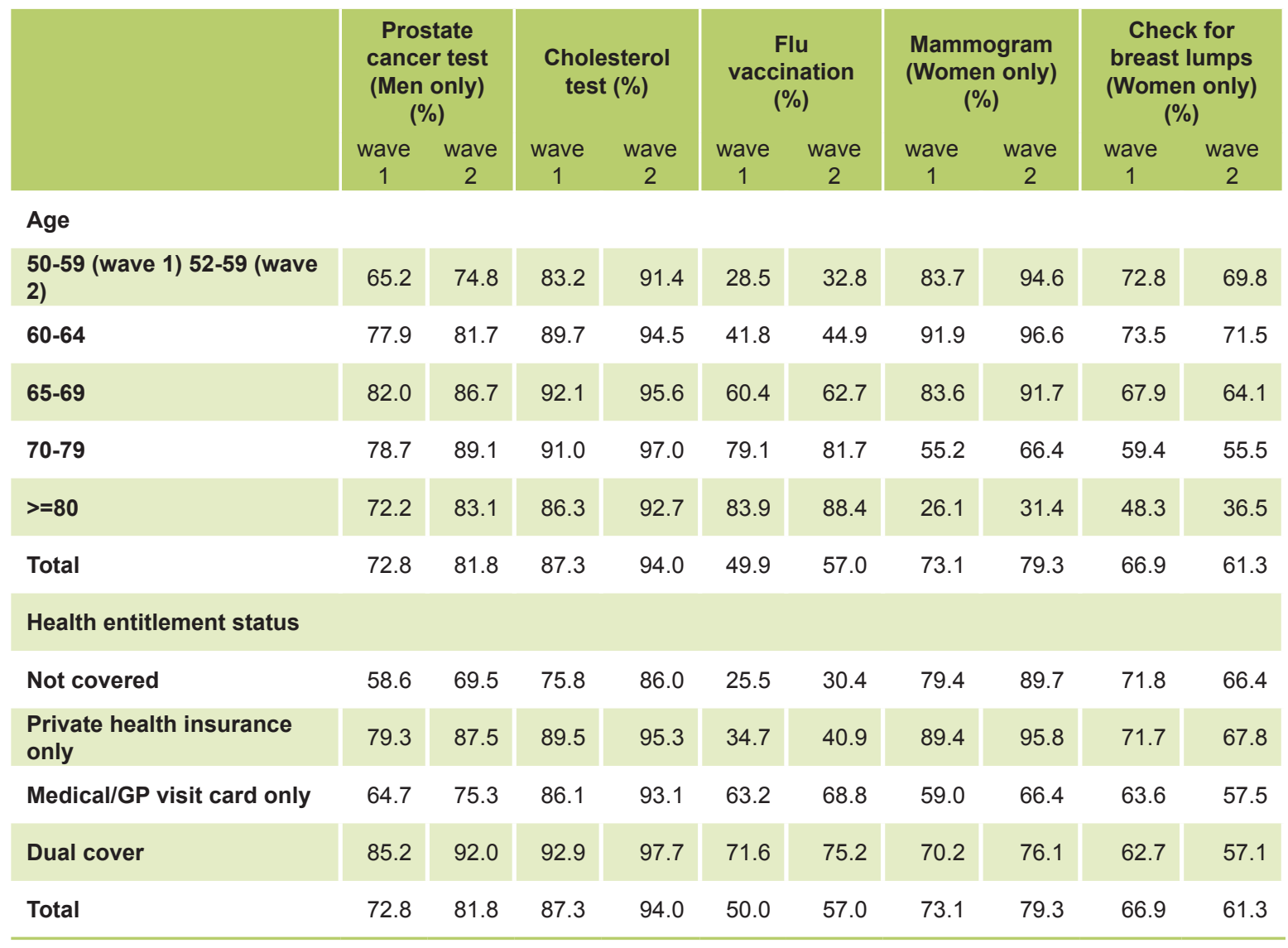

\subsubsection{Cholesterol testing}

Cholesterol testing is widespread in this population of older adults. In wave $187.3 \%$ of those aged 50 years and older had ever had a blood test for cholesterol, and this rose to $94 \%$ at wave 2 in those aged 52 years and older (see Table 5.5). The proportions of men and women tested were similar. 
Cholesterol testing was highest in those with dual cover and lowest in those with no cover. Participants who indicated that they had previously had a blood test for cholesterol carried out at wave 1 were asked in their second interview if they had a repeat test conducted since the time of their first interview. Of these $85 \%$ had a repeat cholesterol test carried out between the two waves. In those that had never had a cholesterol test at wave 1 , $61 \%$ were tested for the first time between their two interviews. More than two thirds of these participants had their cholesterol tested as part of the health assessment in the first wave of TILDA suggesting that the study has impacted on the higher uptake of cholesterol testing at wave 2.

\subsubsection{Flu vaccination}

Annual vaccination for influenza with the most recent virus strains was previously recommended for all adults over 65 years of age but from 2013 it is recommended for all adults over 50 years of age (10). The vaccine is provided free of charge but for those without a medical or GP visit card a consultation fee for administering the vaccine must be paid. A GP consultation costs from $€ 45$ - $€ 60$ or higher compared to a community pharmacy consultation which costs from $€ 15-€ 27.50$ (11-13). Evidence from TILDA suggests that the uptake of the flu vaccine is low overall. In the first wave of TILDA $49.9 \%$ of those over 50 years had ever received a flu vaccination; this increased to $57 \%$ of those aged 52 years and older in wave 2 (see Table 5.5).

A higher proportion of those with dual cover or with medical/GP cards received flu vaccination compared to those with private health insurance only or no cover. Although the vaccine is free to all, less than a third of those with no cover had received a flu vaccination in both waves. This suggests that the GP or pharmacy consultation fees for those without a medical or GP visit card may constitute a barrier to flu vaccination uptake.

There was a high level of repeat flu vaccination $(81 \%)$ in those that had been vaccinated at wave 1. Repeat vaccination was especially high in those aged 80 years and older which reached almost $89 \%$. This suggests that the perceived importance of this vaccine and the acceptability of it are high in this older age group. In those that had never been vaccinated against flu in wave 1 , only $17 \%$ had received a flu vaccination by the time of their interview for wave 2 . These figures are low considering the widespread campaigns for flu vaccination which are run on an annual basis.

\subsubsection{Breast Cancer Screening}

In Ireland the National Breast Screening Programme (BreastCheck) offers women aged 
50-64 years a free mammogram every two years. The proportion of women over 50 years who had ever had a mammogram was $73.1 \%$ in wave 1 . This increased to $79.3 \%$ of those over 52 years at wave 2 (see Table 5.5). The success of this national screening programme is reflected in the fact that breast screening by women in the target age groups is $95 \%$ at wave 2 .

Of those that had a mammogram at wave $165 \%$ had undergone a repeat test in the interwave period. Repeat testing was highest in the younger age groups targeted for screening.

In wave $166.9 \%$ of women over 50 years indicated that they checked their breasts regularly for lumps; and this dropped to $61.3 \%$ of women over 52 years at wave 2 (see Table 5.5). A very clear age gradient can be seen in relation to breast self-examination with a lower proportion of older women conducting breast self-examination.

\subsection{Utilisation of community-based state care services}

Participants were asked if they had utilised any of the community-based state care services in Table 5.6 in the preceding twelve months. They were asked to exclude any services for which they had paid anything other than a token or nominal amount. Unlike utilisation of GP services and acute hospital services which increased between the two waves, three of the community-based services outlined below show decreases in utilisation.

Table 5.6: Proportion utilising community-based state care services

\begin{tabular}{|c|c|c|c|c|c|}
\hline & \multicolumn{2}{|c|}{$\begin{array}{c}\text { wave } 1 \\
(\geq 50 \mathrm{yrs})\end{array}$} & \multicolumn{2}{|c|}{$\begin{array}{c}\text { wave } 2 \\
\text { ( } \geq 52 \mathrm{yrs} \text { ) }\end{array}$} & \multirow{2}{*}{$\begin{array}{c}\text { Change } \\
\text { Between } \\
\text { waves }\end{array}$} \\
\hline & $\%$ & $(95 \% \mathrm{Cl})$ & $\%$ & $(95 \% \mathrm{CI})$ & \\
\hline Public Health or Community Nurse & 6.6 & $(5.9-7.3)$ & 6.5 & $(5.8-7.3)$ & -0.1 \\
\hline Occupational therapy & 1.5 & $(1.2-1.8)$ & 1.7 & $(1.4-2.1)$ & 0.2 \\
\hline Chiropody/podiatry services & 4.5 & $(4.0-5.2)$ & 5.2 & $(4.6-5.9)$ & 0.7 \\
\hline Physiotherapy services & 5.2 & $(4.7-5.7)$ & 5.8 & $(5.2-6.5)$ & 0.6 \\
\hline Psychological/counselling services & 0.8 & $(0.7-1.1)$ & 1.0 & $(0.8-1.3)$ & 0.2 \\
\hline Day centre & 1.2 & $(1.0-1.5)$ & 1.5 & $(1.2-1.8)$ & 0.3 \\
\hline Optician & 12.3 & $(11.3-13.3)$ & 14.8 & $(13.8-15.9)$ & 2.5 \\
\hline Dental services & 10.7 & $(9.9-11.6)$ & 9.2 & $(8.4-10.1)$ & -1.5 \\
\hline Hearing services & 1.8 & $(1.5-2.1)$ & 3.2 & $(2.8-3.7)$ & 1.4 \\
\hline Dietician services & 1.5 & $(1.2-1.8)$ & 1.4 & $(1.2-1.8)$ & -0.1 \\
\hline Respite services & 0.5 & $(0.3-0.7)$ & 0.6 & $(0.4-0.9)$ & 0.1 \\
\hline
\end{tabular}


Utilisation rates range from $14.8 \%$ for optician services to $0.6 \%$ for respite services (see Table 5.6). There was little change in utilisation of community-based services between the two waves. The largest increase can be seen in the optician services, where the proportion of the population utilising the service increased from $12.3 \%$ in wave 1 to $14.8 \%$ in wave 2. Utilisation of dental services, public health nurse or community nurse services and dietician services recorded small decreases between wave 1 and wave 2 .

Almost $70 \%$ of participants in wave 2 use none of these community services. Utilisation is highest in those over 80 years where $59 \%$ of participants use at least one of the services identified.

The vast majority of older people utilising community-based state care services are medical card holders (see Appendix Table 5.A2). An interesting pattern is seen in these data in relation to those with dual cover. The data suggest that those with medical cards as well as private health insurance may also gain additional access to community-based state services where co-payments are a feature of the service. In the case of chiropody/podiatry services, $66 \%$ of users were medical card holders and a further $29 \%$ had dual cover (private health insurance in addition to a medical card or GP visit card) (see Appendix Table 5.A2). Although state chiropody/podiatry services are available to medical card holders, individuals are required to pay an additional co-payment of $€ 15-40$ per visit when attending private practitioners to avail of the service (14). These results suggest that the presence of a co-payment in some services may negatively impact access to services. As health care entitlement status is also strongly related to age and need for health care, this issue requires further investigation.

\subsection{Disability prevalence and utilisation of home care services}

\subsubsection{Disability prevalence}

Disability prevalence will now be discussed in relation to the wave 2 cohort aged 52 years and older. Disability prevalence has been discussed previously in a subgroup in Chapter 4 and will be discussed further in Chapter 6 in a subgroup who completed the self-completion questionnaire. The results in this section are not comparable with either of these chapters due to the different samples used in the analyses.

The prevalence of disability by age and sex is described in Table 5.7. Disability is defined here as difficulty in carrying out activities of daily living (ADL) and instrumental activities of daily living (IADL). ADL are the basic tasks of everyday life that pertain to personal care, 
and six items are included in this scale: difficulty with dressing; walking across a room; bathing or showering; eating, getting in and out of bed; and using the toilet. IADL assesses difficulty in relation to carrying out household activity including: preparing a hot meal; doing household chores; shopping for groceries; making telephone calls; taking medications; and managing money. In the case of both ADL and IADL difficulties, participants were asked to exclude any activities that they expected would last less than three months.

The data revealed a slight increase in the proportion of older people in Ireland who are not disabled ( $87 \%$ in wave 1 to $88 \%$ in wave 2) (see Table 5.7 ). This positive trend can be seen in all age groups under 80 years, however the trend is in the opposite direction in those aged 80 years and older. Systematic differences in the older age category described at the beginning of this chapter may account for some of this difference.

The pattern of disability in wave 2 is broadly similar to wave 1 with more women than men experiencing disability. There is a strong age gradient in disability, only $5 \%$ of the youngest age group in wave 2 experience disability compared to $39 \%$ of those aged 80 years and older (Table 5.7). Although the number of participants aged 90 years and older is small, examination of the data using an expanded age category reveal that $65 \%$ experience some form of ADL or IADL disability (see Appendix Table 5.A3). These findings have particular policy relevance in relation to independent living for older adults and the support required to remain living at home in advanced older age.

Table 5.7: Prevalence of ADL and IADL disability by age and sex

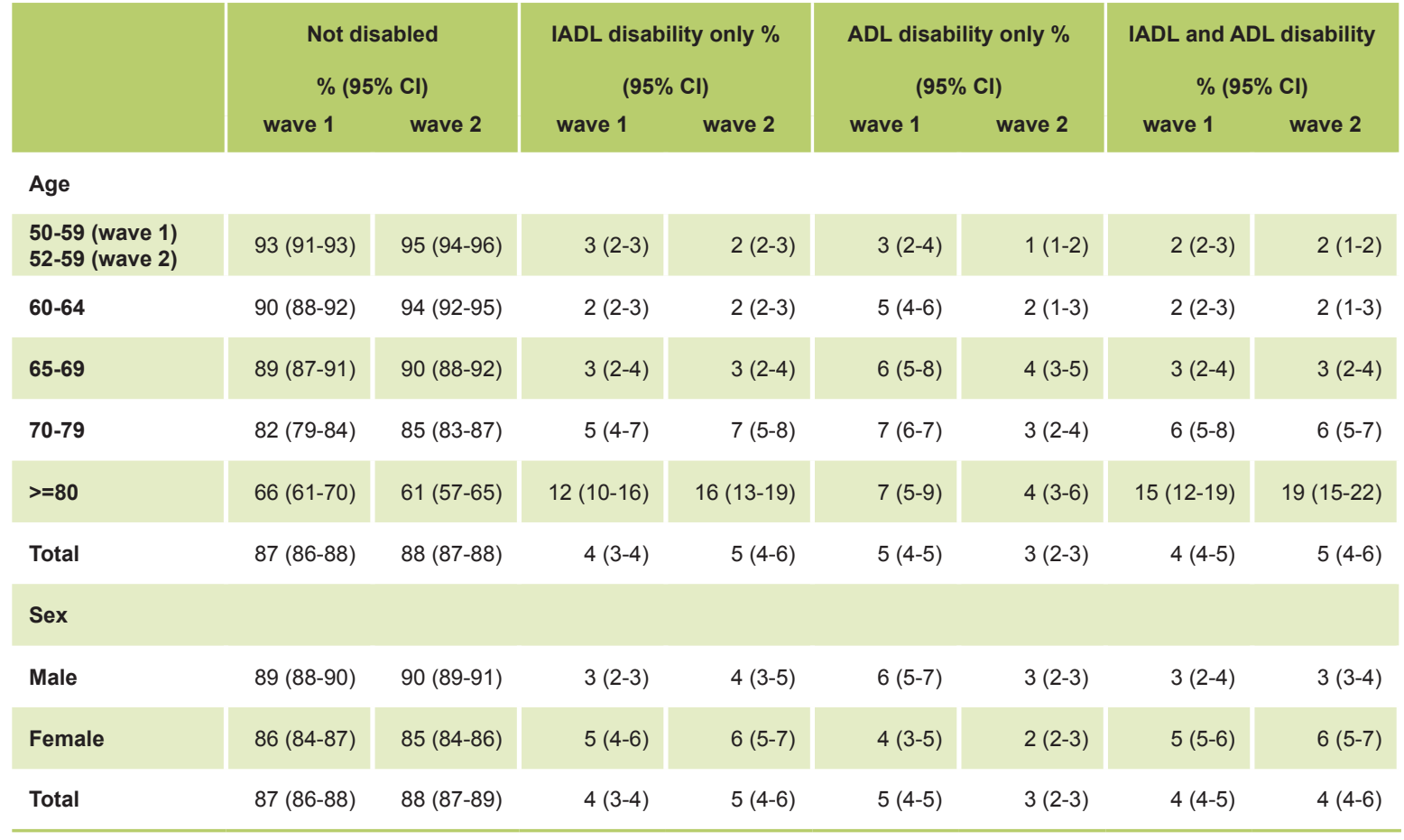


A decrease of two percentage points can be seen between the two waves in ADL disability. In wave 1, participants were asked about difficulty with dressing which included difficulty with putting on socks and shoes. At wave 2 the question was asked about difficulty with dressing only. This change in wording is likely to have impacted on the endorsement of this item in the survey. Future waves will capture both items.

\subsubsection{Utilisation of home help, personal care and meals services}

There was a slight change in the proportions utilising home-based social care services between the two waves. Home help utilisation increased from $3.5 \%$ at wave 1 to $4.4 \%$ at wave 2. In the context of an overall reduction in home help service hours from 11.9 million at the end of 2009 to 11 million hours at the end of 2011, this result appears counter intuitive $(15,16)$. Utilisation is concentrated in those over 80 years with one fifth of this group using home help services at wave 2 (see Table 5.8). It is likely that the increase found is related to the older age profile of community-living participants in this cohort as discussed earlier in this chapter.

Table 5.8: Proportion utilising home help, personal care and meals services by age, sex, health care entitlement status and disability status

\begin{tabular}{|c|c|c|c|c|c|c|}
\hline & \multicolumn{2}{|c|}{ Home help (\%) } & \multicolumn{2}{|c|}{ Personal care attendant (\%) } & \multicolumn{2}{|c|}{ Meals services(\%) } \\
\hline & wave 1 & wave 2 & wave 1 & wave 2 & wave 1 & wave 2 \\
\hline \multicolumn{7}{|l|}{ Age } \\
\hline 50-59 (wave 1) 52-59 (wave 2) & 0.5 & 0.5 & 0.1 & 0.3 & 0.1 & 0.1 \\
\hline $60-64$ & 1.0 & 1.2 & 0.1 & 0.5 & 0.3 & 0.2 \\
\hline $65-69$ & 1.6 & 2.0 & 0.2 & 0.9 & 0.3 & 0.5 \\
\hline $70-79$ & 6.2 & 5.4 & 0.9 & 1.7 & 2.4 & 1.8 \\
\hline$>=80$ & 19.2 & 20.5 & 3.4 & 5.2 & 3.3 & 3.6 \\
\hline Total & 3.5 & 4.4 & 0.6 & 1.3 & 0.9 & 1.0 \\
\hline \multicolumn{7}{|l|}{ Entitlement status } \\
\hline Not covered & 0.1 & 0.6 & 0.0 & 0.0 & 0.0 & 0.0 \\
\hline Private health insurance only & 0.4 & 0.3 & 0.1 & 0.1 & 0.1 & 0.1 \\
\hline Medical card only & 6.7 & 8.3 & 1.2 & 2.5 & 2.0 & 2.0 \\
\hline Dual cover & 5.7 & 5.1 & 0.7 & 1.7 & 1.0 & 0.7 \\
\hline Total & 3.5 & 4.3 & 0.6 & 1.3 & 0.9 & 0.9 \\
\hline \multicolumn{7}{|l|}{ Disability status } \\
\hline Not disabled & 1.8 & 1.9 & 0.2 & 0.2 & 0.5 & 0.4 \\
\hline IADL disability only & 16.6 & 20.5 & 1.1 & 2.4 & 4.6 & 3.3 \\
\hline ADL disability only & 5.2 & 8.2 & 0.8 & 3.2 & 1.4 & 1.1 \\
\hline IADL and ADL disability & 24.0 & 30.1 & 7.9 & 19.8 & 5.3 & 7.9 \\
\hline Total & 3.5 & 4.4 & 0.6 & 1.3 & 0.9 & 1.0 \\
\hline
\end{tabular}


In wave 1 IADL difficulty was found to be a strong driver of home help services for older adults (17). While this continues to be the case in wave 2 it is important to point out that $1.9 \%$ of the non-disabled population (i.e., those that self-report no ADL or IADL difficulty) are availing of home help services (see Table 5.8). While this constitutes a small percentage the numbers are large relative to the total number utilising home help services.

Intensity of home help service utilisation was examined in those that utilised the service in the previous month. The majority $(70 \%)$ received one hour of help on the days when they received home help. The total number of hours of service utilised in the previous month was between one and eight hours for $37 \%$ of home help service users and was greater than 32 hours for just $12 \%$ of service users. These results paint a picture of a home help service which provides a low level of care intensity.

The proportion of the population using personal care services increased from $0.6 \%$ to $1.3 \%$ between the two waves. This result is likely to reflect the increase in the provision of home care packages by the Health Service Executive (HSE). These packages of care provide an enhanced level of support above the normal levels of home help and personal care available from mainstream community services. The number of older people in receipt of home care packages increased from 12,000 at the end of 2009 to 15,000 at the end of 2011(15, 16). The TILDA results reveal that utilisation of personal care services increased from $7.9 \%$ of those with a combined ADL and IADL disability at wave 1 to $19.8 \%$ at wave 2. Although the proportion utilising the service overall is low, the increased utilisation of personal care services by those with higher levels of ADL/IADL disability is consistent with Government policy to provide an enhanced level of home support for older people. Home care packages are allocated on the basis of assessed need and there is no requirement to have a medical card (18). Wave two data indicate that personal care utilisation increased between wave 1 and wave 2 in those with a medical card only (from $1.2 \%$ to $2.5 \%$ ) and in those with dual insurance cover $(0.7 \%$ to $1.7 \%)$. There was no change in the proportions of older people reporting use of meals services between the two waves.

\subsection{Medication use and polypharmacy}

Medication use in the older population is particularly important given the high levels of multi-morbidity and increased predisposition to side effects which comes with age. Polypharmacy, defined as the regular use of 5 or more medicines, is common among the older population and is associated with lower health and increased morbidity. Polypharmacy is often necessary for management of difficult illnesses or conditions, which require complex care. However, inappropriate or over-prescribing is also a factor, exposing 
patients to risks of drug interactions and adverse drug reactions.

Changes in medication use in participants who took part in wave 1 and wave 2 is examined in Table 5.9. Total prevalence of medication use in wave 1 is displayed in the first column and total prevalence at wave 2 in the last row. As expected medication use has increased as the cohort is two years older. At wave $121 \%$ of participants reported using 5 or more medications regularly, and this increased to $26 \%$ in wave 2 . Correspondingly, the number of participants reporting no regular medication use dropped from $28 \%$ in wave 1 to $24 \%$ in wave 2.

Changing patterns of medication use is also examined in Table 5.9. For those who have increased their medication use in wave 2 the majority have just moved up one group. For example of those who were not regularly taking medications at wave 1 , the majority $69 \%$ were still not taking any regular medications at wave 2 while $24 \%$ had progressed to the 1-2 medications group. The same holds true for the other groups. The numbers who have significantly increased their medication use is relatively low; $2 \%$ of those using no medication and $7 \%$ of those using $1-2$ medications in wave 1 are now in the polypharmacy category ( $5+$ medications). While the prevalence of polypharmacy has increased overall, $15 \%$ of those who were taking 5 or more medications regularly in wave 1 have reduced their medication use in wave 2 .

Table 5.9: Changes in medication use between wave 1 and wave 2

\begin{tabular}{|c|c|c|c|c|c|c|c|}
\hline & $\begin{array}{c}\text { Total } \\
\text { (wave 1)\% }\end{array}$ & $\begin{array}{c}0 \\
\text { Medications } \\
\text { (wave 2) } \\
\%\end{array}$ & $\begin{array}{c}1-2 \\
\text { Medications } \\
\text { (wave 2) } \\
\%\end{array}$ & $\begin{array}{c}\text { 3-4 } \\
\text { Medications } \\
\text { (wave 2) } \\
\%\end{array}$ & $\begin{array}{c}5+ \\
\text { Medications } \\
\text { (wave 2) } \\
\%\end{array}$ & Total & $\begin{array}{l}\text { Number } \\
\text { in sample }\end{array}$ \\
\hline 1-2 Medications (wave 1) & 29 & 8 & 62 & 23 & 7 & 100 & 2215 \\
\hline 3-4 Medications (wave 1) & 21 & 2 & 14 & 52 & 33 & 100 & 1377 \\
\hline 5+ Meds (wave 1) & 21 & 1 & 2 & 12 & 85 & 100 & 1216 \\
\hline
\end{tabular}

Figure 5.1 breaks down the wave 2 numbers by 5-year age groups, revealing a broadly linear increase with age in the mean number of medications used until age 80 , after which it levels off at age $85+$.

Further information on medication use in wave 2 by both age and sex is available in 
Appendix Figure 5.B1. Men report less medication use than women, particularly in the age range 52-64 years. This trend decreases over age, with both sexes reporting nearly the same medication use after age 75. Larger proportions of the older age groups use more medications, with nearly $50 \%$ of those aged 75 years and over reporting polypharmacy. Reporting higher medication use is also strongly associated with lower education, lower self-rated health and decreased physical activity (see Appendix Tables 5.A4-5.A6).

Figure 5.1: Mean number of medications (excluding food supplements) used in wave 2 by age

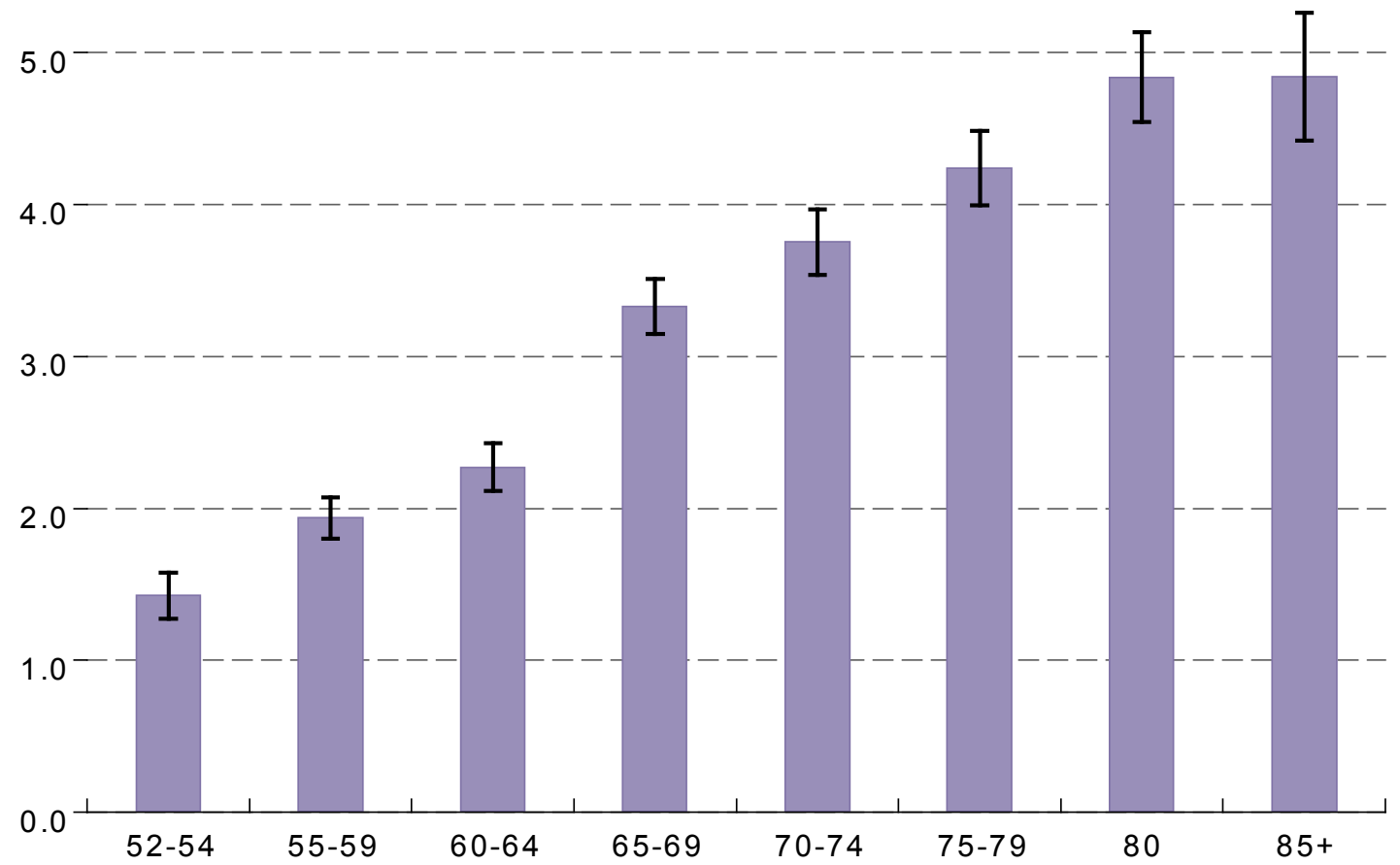

Note. $\mathrm{N}=7282$; Missing obs $=0$; Error bars correspond to $95 \%$ confidence intervals

The five most common medications has remained similar across both waves with a slight alteration in order (see Table 5.10). Medication classes (ATC level 2) and food supplements have remained the same. Food supplements were defined according to the European Directive 2002/46/EC as any substance with a nutritional effect which is taken to supplement the normal diet. The five most frequently reported food supplements account for a similar proportion of the total supplements used ( $79 \%$ in wave 1 and $78 \%$ in wave 2). 
Table 5.10: Top five most commonly used medications, medication classes and food supplements

\begin{tabular}{|c|c|c|c|c|c|c|}
\hline & \multicolumn{2}{|c|}{$\begin{array}{l}\text { Individual medications } \\
\text { (International Non- } \\
\text { proprietary name) }\end{array}$} & \multicolumn{2}{|c|}{$\begin{array}{l}\text { Medication classes } \\
\text { (ATC Level 2) }\end{array}$} & \multicolumn{2}{|c|}{ Food supplements } \\
\hline & wave 1 & wave 2 & wave 1 & wave 2 & wave 1 & wave 2 \\
\hline 1 & Aspirin & Aspirin & $\begin{array}{l}\text { Lipid modifying } \\
\text { agents }(\mathrm{C} 10)\end{array}$ & $\begin{array}{l}\text { Lipid modifying } \\
\text { agents }(C 10)\end{array}$ & $\begin{array}{l}\text { Calcium } \\
\text { carbonate, } \\
\text { combinations }\end{array}$ & $\begin{array}{c}\text { Calcium } \\
\text { carbonate, } \\
\text { combinations }\end{array}$ \\
\hline 2 & Atorvastatin & Atorvastatin & $\begin{array}{l}\text { Agents acting } \\
\text { on the rennin- } \\
\text { angiotensin } \\
\text { system (C09) }\end{array}$ & $\begin{array}{l}\text { Agents acting } \\
\text { on the rennin- } \\
\text { angiotensin } \\
\text { system (C09) }\end{array}$ & $\begin{array}{l}\text { Omega-3- } \\
\text { triglycerides }\end{array}$ & $\begin{array}{l}\text { Omega-3- } \\
\text { triglycerides }\end{array}$ \\
\hline 3 & Levothyroxine & Rosuvastatin & $\begin{array}{l}\text { Anti-thrombotic } \\
\text { drugs (B01) }\end{array}$ & $\begin{array}{l}\text { Anti-thrombotic } \\
\text { drugs (B01) }\end{array}$ & Glucosamine & Glucosamine \\
\hline 4 & Bisoprolol & Bisoprolol & $\begin{array}{l}\text { Drugs for acid } \\
\text { related disorders } \\
\text { (A02) }\end{array}$ & $\begin{array}{l}\text { Drugs for acid } \\
\text { related disorders } \\
\text { (A02) }\end{array}$ & $\begin{array}{l}\text { Vitamin B, } \\
\text { combinations }\end{array}$ & $\begin{array}{l}\text { Vitamin B, } \\
\text { combinations }\end{array}$ \\
\hline 5 & Rosuvastatin & Levothyroxine & $\begin{array}{l}\text { Beta blocking } \\
\text { agents (C07) }\end{array}$ & $\begin{array}{l}\text { Beta blocking } \\
\text { agents (C07) }\end{array}$ & Multivitamins & Multivitamins \\
\hline
\end{tabular}

\subsubsection{Use of generics: the case of Atorvastatin}

Statins are one of the most commonly prescribed medicines in the older population and generate the largest expenditure (19). They are used to help lower low density lipoprotein cholesterol (LDL-C) in the prevention and treatment of cardiovascular disease. When looking at generic drug use we can use four broad categories of drug type: pure generic which is sold using the active pharmaceutical name (e.g. Atorvastatin); branded generic which is sold using a marketing name (e.g. Torvacol); proprietary brand with a generic equivalent (e.g. Lipitor); proprietary brand without a generic equivalent (i.e. a drug still under patent protection). Generic medicines are usually cheaper than the proprietary brand, and thus they provide the same level of medication intervention at a lower cost. Of all the medications used by the older population only $20 \%$ were generics at wave 1 with a slight increase to $22 \%$ at wave 2 . There is a more dramatic increase in generic use for the statin group of medications, with the proportion of generics increasing from $8.5 \%$ at wave 1 to $23.5 \%$ at wave 2 due to the expiry of patents. Between the first and second waves of TILDA data collection the most prevalent statin, Atorvastatin, came off patent which allowed the entry of generic competitor medicines by wave 2 . This provides an interesting insight into the initial effect of a drug patent expiry on medication use. 
Table 5.11: Generic share of Atorvastatin at wave 2 by wave 1 use and medical card status

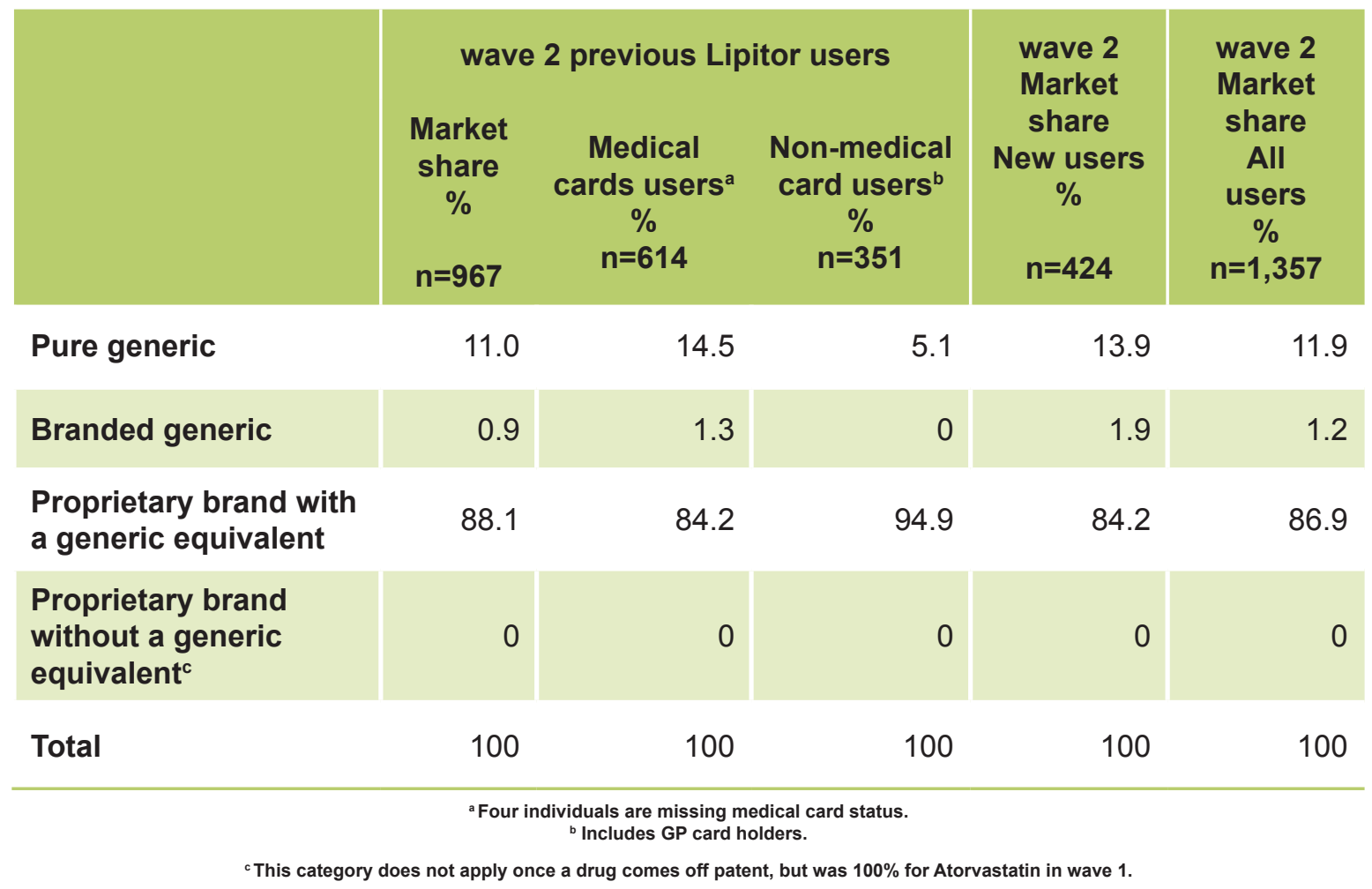

Atorvastatin accounts for $57 \%$ of all statin use in wave 1 and $56 \%$ in wave 2 , in addition to being the second most used medication in both waves. Table 5.11 shows the effect of the patent expiry on Lipitor (the branded version of Atorvastatin, which did not have a generic equivalent in wave 1) which occurred during the inter-wave period. While some individuals who were using Lipitor in wave 1 have moved to generic versions (11\%) the majority of patients have remained on the proprietary brand $(88.1 \%)$. This is most evident in those who do not have a medical card, with $94.9 \%$ remaining on the proprietary brand. This contrasts sharply with previous Lipitor users in England where only $31 \%$ of patients have initially remained on the proprietary brand (20). Evidence from TILDA wave 2 suggests that private patients (i.e., those without a medical card) in this case are more resistant to generic substitution, with only $5 \%$ switching. In general there is a higher use of generics in wave 2 among those who were not previously using Lipitor.

Two recent measures should have a considerable impact on future prescribing patterns in Ireland. Firstly, the HSE has commenced a medicines management programme to encourage cost effective prescribing. As part of this programme, Simvastatin has been designated the preferred statin for initial treatment. Secondly, the Health (Pricing and Supply of Medical Goods) Act 2013 has introduced the legislation to implement generic substitution at the pharmacy level and a system of drug group reference pricing for reimbursement (21). Generic substitution for Atorvastatin was introduced in August 2013 
and drug group reference pricing was introduced in November 2013. The effects of both of these measures will be visible in future waves of TILDA.

\subsection{Health service utilisation at the end of life}

In this section the health service use of those who died since wave 1 of the TILDA survey is described. Patterns of service use among the deceased are compared to participants who were still alive at wave 2 . At the end of wave 2 data collection, there were a total of 205 deaths among participants. Data from 'end of life' interviews were available from 155 individuals acting as a proxy participant for deceased participants. Most proxy participants were relatives of the deceased participant including the son or daughter (including inlaw) $(43.8 \%)$, or the spouse or partner of the deceased $(30.9 \%)$. Other proxy participants included siblings $(7.7 \%)$, other relatives $(8.4 \%)$ and other non-relatives $(8.4 \%)$. The end of life interview included questions on use of health services in the 12 months before the TILDA participant died, his/her physical and behavioural health, cognitive function and financial circumstances.

Of those who died, $55 \%$ were men and the average age of the deceased was 75.5 years (median 77 years). Most of those who died were married (40.6\%) or widowed $(40.0 \%)$ and $19.3 \%$ were single separated or divorced at the time of death. Almost half of the deceased died in hospital (48.4\%), approximately one quarter died at home $(24.5 \%)$ and $9.7 \%$ died in a nursing home or residential care setting. Approximately $13 \%$ died in a hospice and $4.5 \%$ died at other locations.

The most common causes of death reported by proxy participants were cancer (37.5\%), followed by cardiovascular-related causes $(28.9 \%)$, other causes such as digestive disorders, infectious disease, accidents $(21.1 \%)$ and respiratory causes $(12.5 \%)$. There were no differences between men and women in terms of the main causes of death. There was some evidence that more people died from respiratory diseases in the older age groups (3.4\% of those aged $50-64$ compared to $13.3 \%$ of those aged $65-74$ and $15.2 \%$ of those aged $\geq 75$ years) but the association between age and cause of death was not statistically significant. In terms of physical health prior to death, $41.3 \%$ of proxy participants described the deceased as mostly active and disability free but declining during the last few months before death. In total, $25.8 \%$ of proxy participants reported that the deceased had been ill for one year or more before he/she died. 
Table 5.12: Proportion of deceased and survivors utilising primary and secondary care services at wave 2

\begin{tabular}{|l|cr|cr|}
\hline & \multicolumn{2}{|c|}{ Deceased } & \multicolumn{2}{c|}{ wave 2 Survivors } \\
\hline GP visit & $\%$ & $(95 \% \mathbf{C l})$ & $\%$ & $(95 \% \mathrm{CI})$ \\
\hline Outpatient & 87.1 & $(81.8-92.4)$ & 89.6 & $(88.7-90.2)$ \\
\hline Emergency Department & 44.5 & $(36.7-50.5)$ & 45.0 & $(43.4-46.2)$ \\
\hline Hospital admission & 59.4 & $(51.5-67.2)$ & 14.6 & $(15.3-17.2)$ \\
\hline
\end{tabular}

Table 5.12 shows the pattern of utilisation of different types of health services in the 12 months before death. Health service use in the deceased group is compared to those survivors who participated in wave 2 . The percentages are for those who used the services at least once in the previous year. The majority of those who died had attended the GP in the 12 months before death according to the proxy respondent. In contrast, less than half had attended an out-patient clinic or the ED. A higher proportion of people who died had attended an ED or had a hospital admission in the 12 months preceding death compared to participants in wave 2 .

The end-of-life interviews also allow for an examination of the proportions of deceased individuals who received three types of state-provided home care services in the last 12 months of life: home help, meals services and the services provided by personal care attendants. Approximately $25 \%$ of deceased individuals received home help in the year preceding death, $11 \%$ had the help of a state-provided personal care attendant and $7.7 \%$ received meals services (Table 5.13). The majority of proxy respondents reported that the deceased received none of the state services outlined above (67.1\%). A higher proportion of those who died were utilising state-provided home services in the preceding 12 months, compared to survivors at wave 2 .

Table 5.13: Proportion of deceased and survivors utilising home help, personal care and meals services at wave 2

\begin{tabular}{l|cr|cr|} 
& \multicolumn{2}{|c|}{ Deceased } & \multicolumn{2}{c|}{ wave 2 Survivors } \\
& $\%$ & $(95 \% \mathrm{CI})$ & $\%$ & $(95 \% \mathrm{CI})$ \\
\hline Home help & 25.2 & $(18.3-32.1)$ & 4.4 & $(3.5-4.6)$ \\
\hline Personal care attendant & 11.0 & $(6.0-15.9)$ & 1.3 & $(0.9-1.5)$ \\
\hline Meals services & 7.7 & $(3.5-12.0)$ & 1.0 & $(0.7-1.2)$ \\
\hline
\end{tabular}




\subsection{Conclusion}

Maintaining and improving population health and well-being is a key goal of Irish health policy. Current Government policy aims to manage and prevent illness at the earliest stage possible (22). It is encouraging to find that the uptake of primary prevention and screening programmes has increased in the older population across the first two waves of TILDA, although there is some evidence that those without a medical card or GP visit card may face access barriers with regard to flu vaccination. The data identify a reduction in the proportion of older people over 70 years with full access to primary and secondary care services at a time in their life when their need for health and social care is increasing, especially in the period at the end of life. Current health service reforms are aimed at reducing the reliance on secondary care services and providing integrated primary and community-based care where possible. The findings in this chapter reveal a continued and increasing utilisation of primary GP services and secondary care services but minimal change in the community health and social care sector.

\section{References}

1. Government of Ireland. Health (Alteration of Criteria for Eligibility) Act 2013. In: Department of Health, editor. Dublin: Government Publications, 2013.

2. Reilly J. Opening Statement by the Minister for Health, Dr. James Reilly TD, at the Joint Oireachtas Committee on Health and Children, 2013.

3. Health Service Executive. Medical Card/GP Visit Card National Assessment Guidelines for People aged 70 years and over. Dublin: Health Service Executive, 2013.

4. Department of Health. Health in Ireland: Key Trends 2012. Dublin: Department of Health, 2012.

5. Department of Health and Children. Health in Ireland Key Trends 2010. Dublin: Department of Health and Children, 2010.

6. Health Insurance Authority. The Health Insurance Authority Annual Report and Accounts 2012. Dublin: Health Insurance Authority, 2013.

7. Central Statistics Office. Survey on Income and Living Conditions (SILC) Thematic Report on the Elderly. Dublin: Central Statistics Office, 2013.

8. National Cancer Registry. Cancer in Ireland 2013: Annual Report of the National Cancer Registry. Cork: National Cancer Registry Ireland, 2013.

9. Department of Health and Children. A Strategy for Cancer Control in Ireland. Dublin: 
Department of Health and Children, 2006.

10. Health Service Executive. Chapter 11: Influenza. 2013. In: Immunisation guidelines for Ireland (Internet). Dublin: HSE, ICGP, HPSC. Available from: http://www.immunisation. ie/en/Downloads/NIACGuidelines/PDFFile_17361_en.pdf.

11. Pharmhealth integrative pharmacy. Pharmacy-services winter flu vaccination service 2013 (cited 2013 6/12/13). Available from: http://www.pharmhealth.ie/Pharmacyservices/winter-flu-vaccination-service.html.

12. Travel Health. Flu Vaccine Dublin,2013 (cited 2013 6/12/13). Available from: http://www. travelhealth.ie/FluVaccine/

13. The Competition Authority. Competiton in Professional Services: General Medical Practitioners. Dublin: The Competiton Authority, 2010.

14. Chiropody service. Advertisment for fees including Co-payment for chiropody card holders 2013 (cited 2013 9/12/13). Available from: http://www.treesroad.com/fees.htm; http://www.spectrumhealth.ie/our-fees/.

15. Department of Health and Children. Annual Output Statement 2010 for Health Group Votes. Dublin: Department of Health and Children, 2010.

16. Department of Health. Annual Output Statement for Health Group Votes 2012-38 and 39. Dublin: Department of Health, 2012.

17. Murphy C. Unpublished PhD thesis: The Distribution and Determinants of Home-Based Social Care Utilisation in Older People: Irish and Comparative Perspectives: Dublin, Trinity College; 2012.

18. Health Service Executive. National Guidelines and Procedures for Standardised Implementation of the Home Care Package Scheme. Dublin: Health Service Executive, 2010.

19. Primary Care Reimbursement Service. Statistical analysis of claims and payments 2011. Dublin: Health Service Executive, 2012.

20. Leonard S.A. Wilson T.L. Hamerslaget, L. Patterns of Generic and Proprietary Prescribing of Statins Over Time in England. Value in Health. 2013;16(7):A328.

21. Government of Ireland. Health (Pricing and Supply of Medical Goods) Act 2013. Government of Ireland; 2013.

22. Layte R, Sexton E, Savva G. Quality of Life in Older Age: Evidence from an Irish Cohort Study. Journal of the American Geriatrics Society. 2013;61:S299-S305. 


\section{Appendix 5A: Tables on Health and Social Care Utilisation}

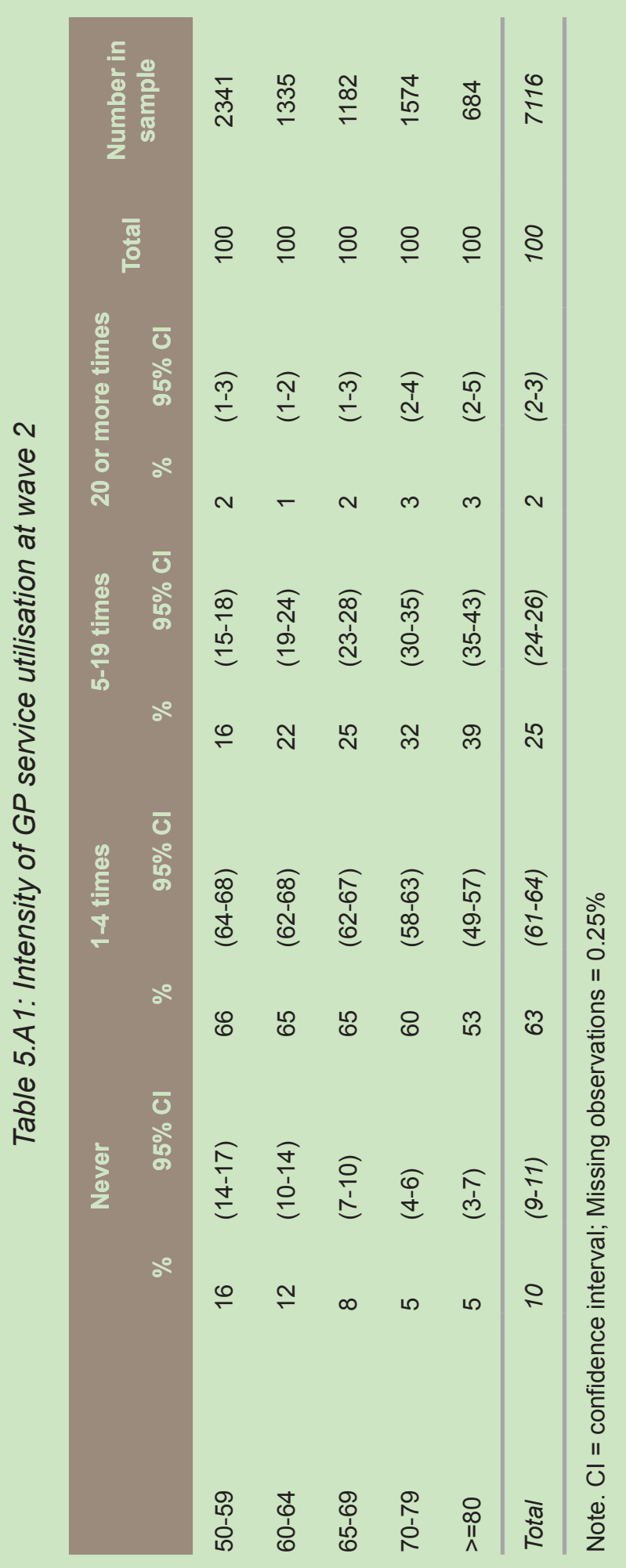




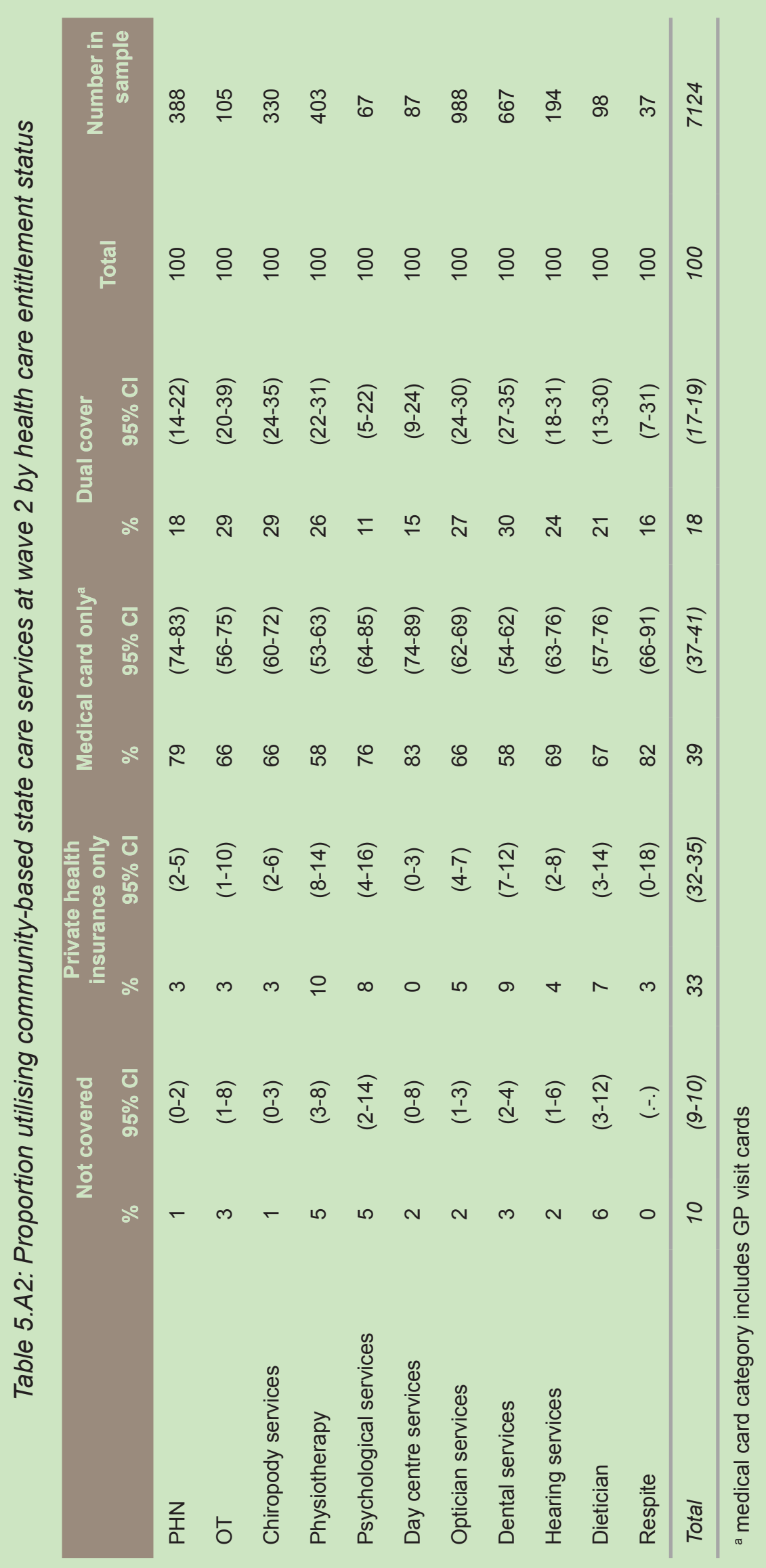




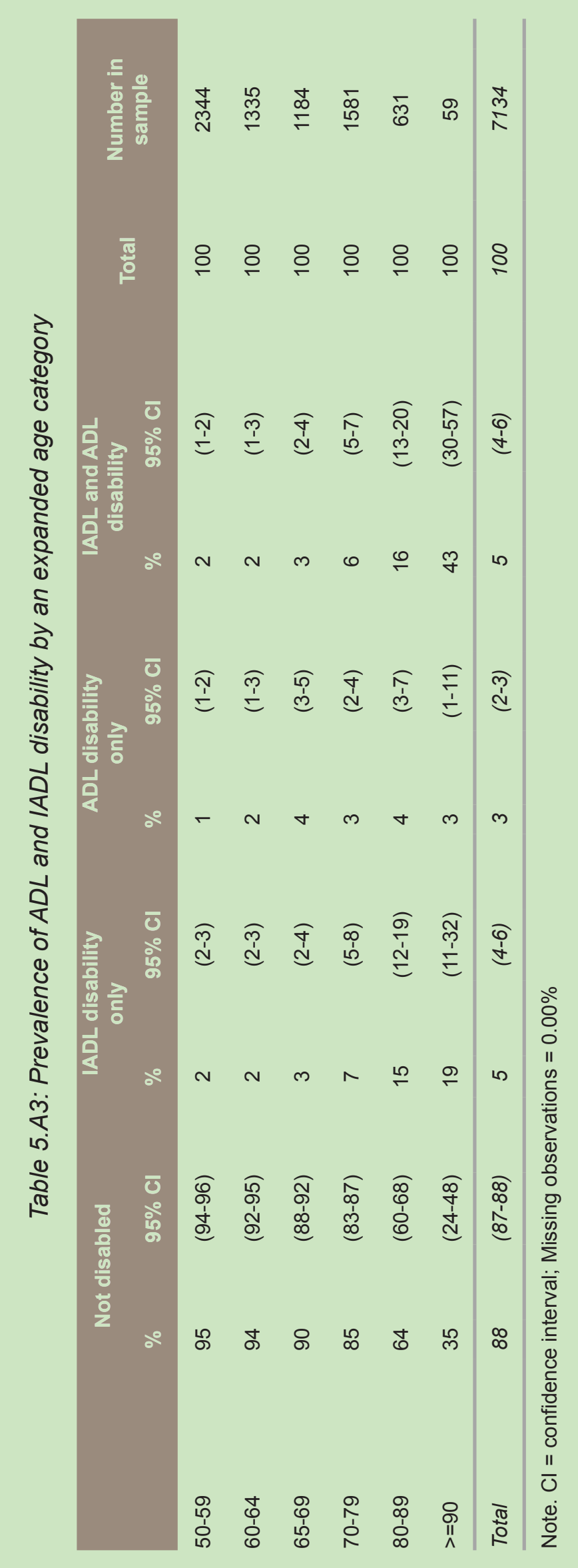



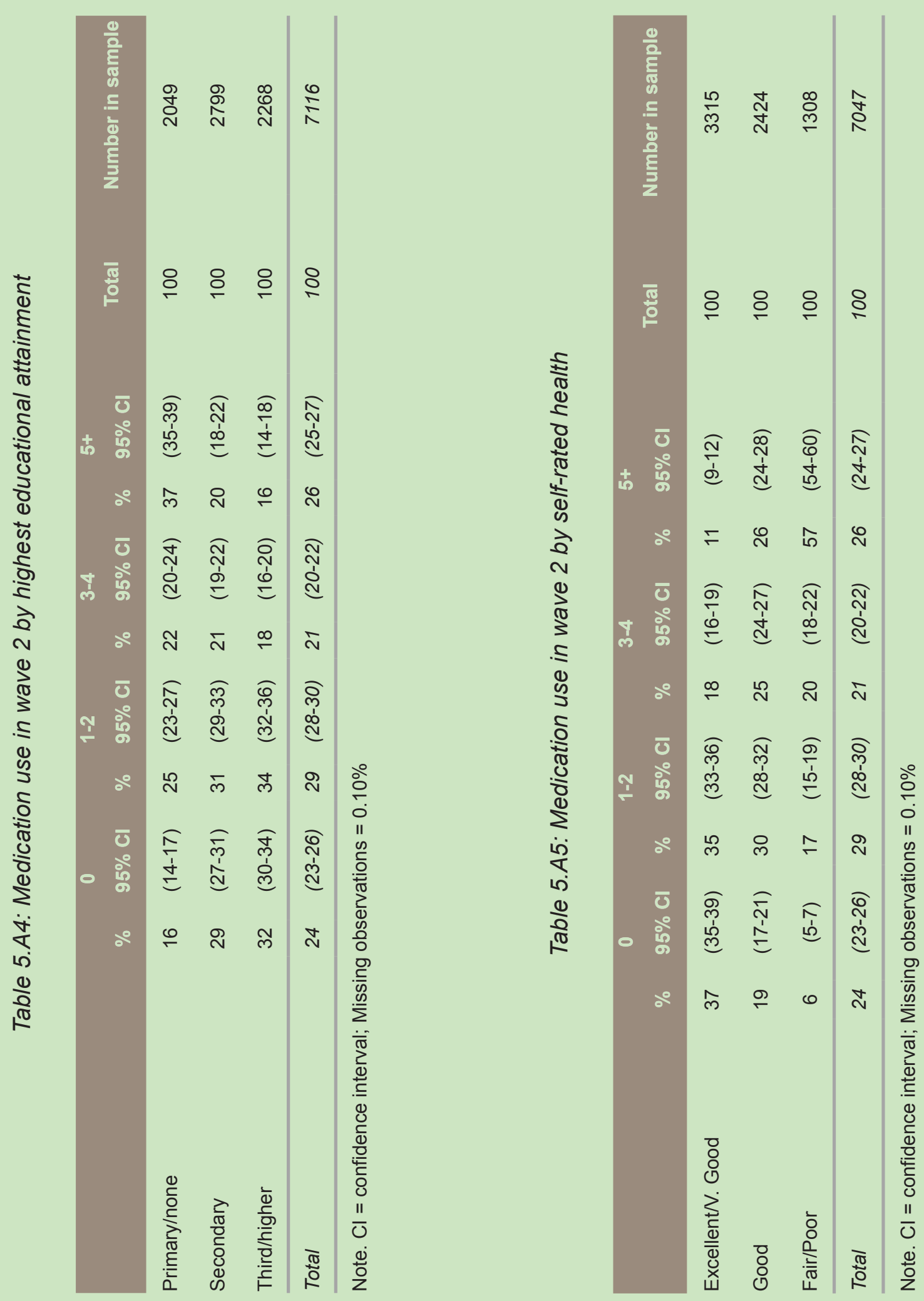


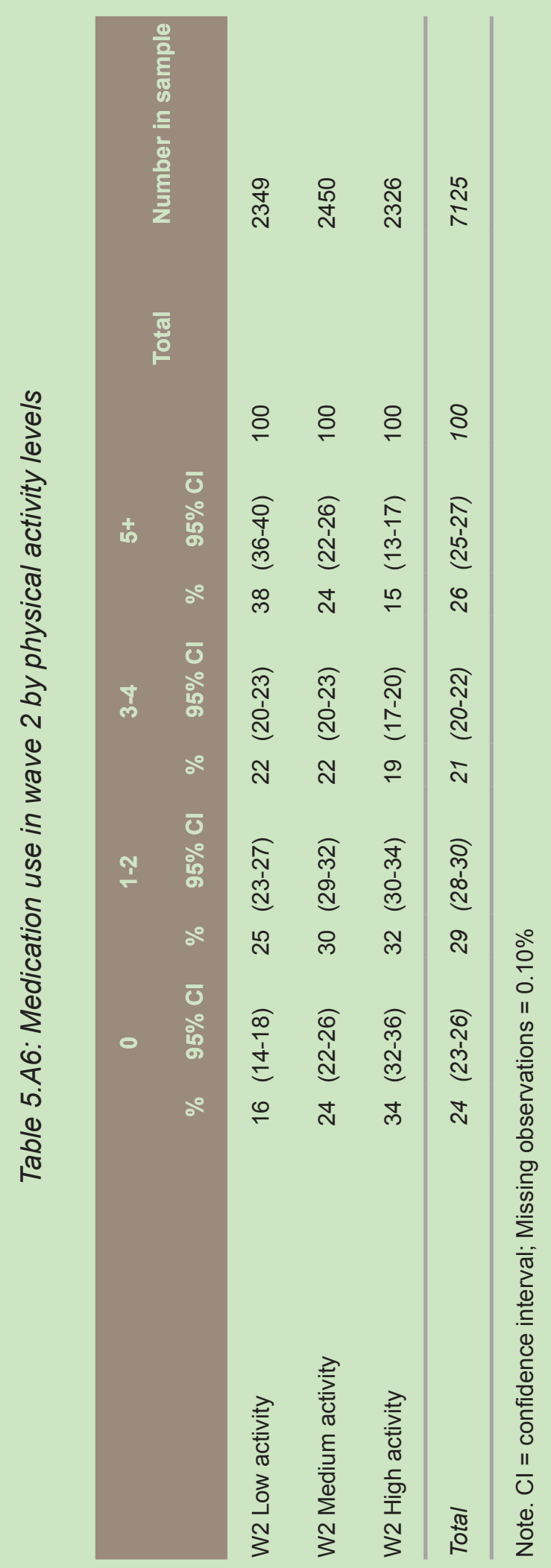




\section{Appendix 5B: Figures on Health and Social Care Utilisation}

Figure 5.B1: Medication use in wave 2 by age and sex

\begin{tabular}{l|l|l|l|}
0 & $1-2$ & $3-4$ & $5+$
\end{tabular}
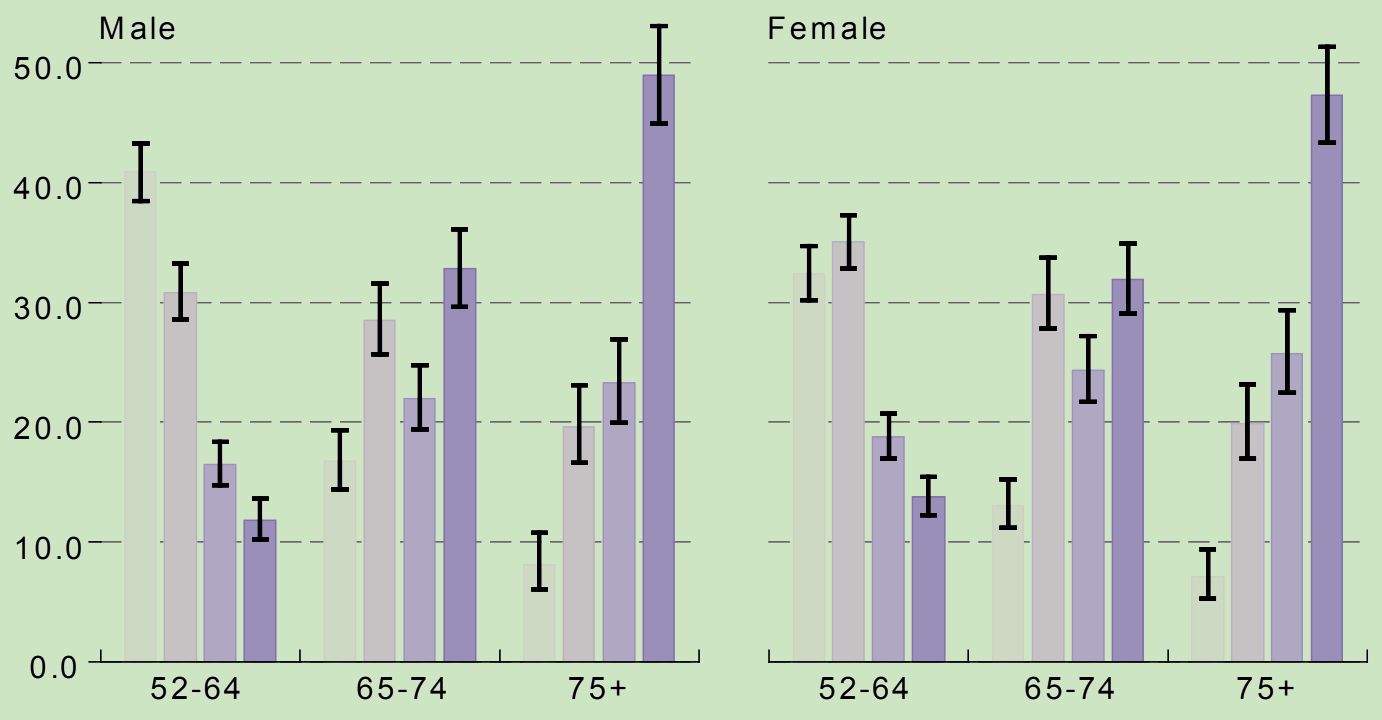

Note. $\mathrm{N}=7127$; Missing obs $=7$; Error bars correspond to $95 \%$ confidence intervals 